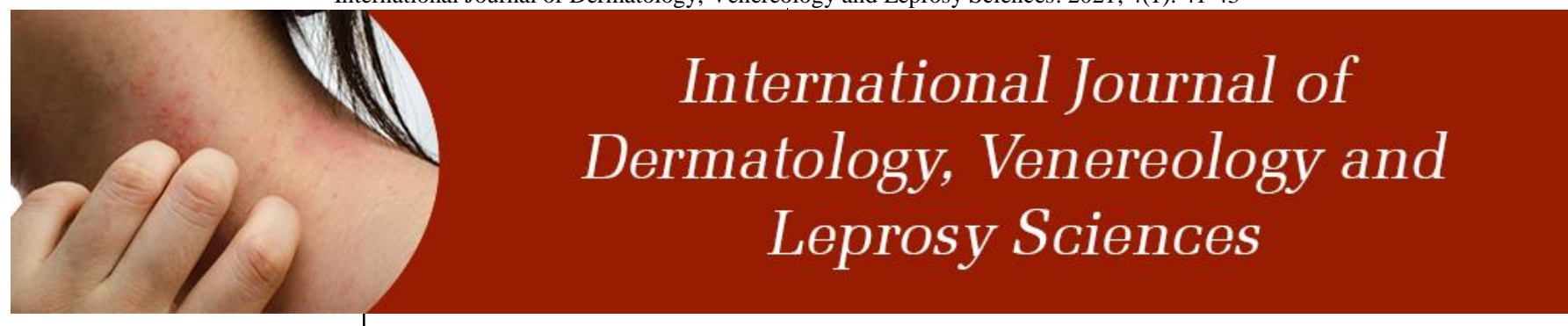

E-ISSN: 2664-942X P-ISSN: 2664-9411 www.dermatologypaper.com Derma 2021; 4(1): 41-43 Received: 15-12-2020 Accepted: 20-01-2021

Dr. Shwetha V Rajiv Assistant Professor, Department of Dermatology, Malabar Medical College, Madakkallur, Calicut, Kerala, India
Corresponding Author: Dr. Shwetha V Rajiv Assistant Professor, Department of Dermatology, Malabar Medical College, Madakkallur, Calicut, Kerala, India

\section{A study of effectiveness of online classroom learning vs online live consultation based learning in the department of dermatology: A Likert scale and MCQs based Google form study}

\author{
Dr. Shwetha V Rajiv
}

DOI: https://doi.org/10.33545/26649411.2021.v4.i1a.68

\begin{abstract}
Teaching in Dermatology is not easy especially in COVID situations to MBBS students. The COVID19 pandemic has had a significant impact on all aspects of normal life. Teaching and learning, at all levels have also been affected, including clinical teaching in medical schools. Direct patient interaction, especially in groups, in out-patient departments or wards, is difficult. To add to this, patients have also reduced visits for nonemergency reasons. Institutes have adapted to the changed circumstances by increasing the use of online learning. Online education has its own limitations, especially in medical education, more so in the context of clinical rotations. Dermatology, being an inherently visual specialty, probably is more amenable to online learning as compared to other specialties. We describe our experience and the student and faculty feedback after an online Dermatology teaching module for undergraduate medical students, which was created in lieu of traditional teaching, due to the restrictions imposed by the pandemic. This study puts to find the student's perceptions and the impact of the programme on the learning of students to be beneficial to the faculty in the future. The primary objective is to evaluate the perception of the students and teachers towards online teaching. The secondary objective is to evaluate the performance of students.
\end{abstract}

Keywords: Online classroom, online live consultation, Likert scale, MCQ

\section{Introduction}

The Corona pandemic called as the COVID 19 pandemics by the WHO has gripped the world and the tentacles are spreading ${ }^{[1]}$. Perhaps this pandemic has given us a suitable platform to scratch our brains and think what is happening in the Medical School? Teaching in Medical education especially the theoretical part was done by taking traditional lectures in classrooms ${ }^{[3-6]}$. A large number of people can be trained at a single point in time. This is a boon especially in our country where Medical faculties are not easily available ${ }^{[7-9]}$. But we are so much used to this system that we are feeling troubled even by the thought of bringing a change ${ }^{[10]}$. In desperate times the need of the hour is taking desperate actions. It is rightly said that necessity is the mother of all inventions. This study puts to find the student's perceptions and the impact of the programme on the learning of students to be beneficial to the faculty in the future. The primary objective is to evaluate the perception of the students and teachers towards online teaching. The secondary objective is to evaluate the performance of students.

\section{Aims and Objectives}

To study the effectiveness of online learning implemented in the Department of Dermatology.

\section{Materials and Methods}

This study was done in Department of Dermatology, Malabar Medical College, Madakkallur, Calicut, Kerala.

This study was done in 100 students.

They were divided into 2 groups. Each group had 50 students. 
50 students were made to undergo live classroom online based teaching. The teachers would take the class and online coverage of the class was broadcasted to the students.

The other 50 were made to watch the online live consultation of the patients and then the explanation was done by the doctor live.

The perception scale which was prepared was sent to the students via Google forms after 5 such sessions. On the next day the MCQ test was organized and the scores were collected.

Once the college started one more MCQ test was organized and the scores were collected and reported.

\section{Results}

Table 1: Independent $t$ test to compare between the two groups

\begin{tabular}{|c|c|c|c|c|c|c|c|}
\hline & Group & $\mathbf{N}$ & Mean & Std. deviation & $\mathbf{t}$ & df & P Value \\
\hline \multirow{2}{*}{ Perception } & Classroom & 50 & 38.12 & 7.105 & \multirow{2}{*}{-9.603} & \multirow{2}{*}{60.368} & \multirow{2}{*}{$<0.001$} \\
\hline & Patient consultation & 50 & 48.32 & 2.436 & & & \\
\hline \multirow{2}{*}{ MCQ } & Classroom & 50 & 5.98 & 2.208 & \multirow{2}{*}{-8.062} & \multirow{2}{*}{70.971} & \multirow{2}{*}{$<0.001$} \\
\hline & Patient consultation & 50 & 8.78 & 1.075 & & & \\
\hline \multirow{2}{*}{ MCQ-After } & Classroom & 50 & 3.9 & 1.693 & \multirow{2}{*}{-9.531} & \multirow{2}{*}{98} & \multirow{2}{*}{$<0.001$} \\
\hline & Patient consultation & 50 & 7.06 & 1.621 & & & \\
\hline \multirow{2}{*}{ MCQ difference } & Classroom & 50 & 2.08 & 2.641 & \multirow{2}{*}{0.804} & \multirow{2}{*}{85.084} & \multirow{2}{*}{0.424} \\
\hline & Patient consultation & 50 & 1.72 & 1.75 & & & \\
\hline
\end{tabular}

Table 2: Paired t test for comparison of the before and after values in each group separately

\begin{tabular}{|c|c|c|c|c|c|c|c|c|c|}
\hline \multirow{2}{*}{ Group } & & \multirow{2}{*}{$\mathbf{N}$} & \multirow{2}{*}{ Mean } & \multirow{2}{*}{ Std. deviation } & \multicolumn{2}{|c|}{ Paired differences } & \multirow{2}{*}{$\mathbf{t}$} & \multirow{2}{*}{ df } & \multirow{2}{*}{ P Value } \\
\hline & & & & & Mean difference & Std. deviation & & & \\
\hline \multirow{2}{*}{ Classroom } & MCQ & 50 & 5.98 & 2.208 & \multirow{2}{*}{2.08} & \multirow{2}{*}{2.641} & \multirow{2}{*}{5.57} & \multirow{2}{*}{49} & \multirow{2}{*}{$<0.001$} \\
\hline & MCQ-After & 50 & 3.9 & 1.693 & & & & & \\
\hline \multirow{2}{*}{ Patient consultation } & MCQ & 50 & 8.78 & 1.075 & \multirow{2}{*}{1.72} & \multirow{2}{*}{1.75} & \multirow{2}{*}{6.949} & \multirow{2}{*}{49} & \multirow{2}{*}{$<0.001$} \\
\hline & MCQ-After & 50 & 7.06 & 1.621 & & & & & \\
\hline
\end{tabular}

\section{Discussion}

Comparison of the Perception between the two groups shows that Perception is higher in online consultation based learning group with a $t$ value of -9.603 and is statistically significant with a $\mathrm{p}$ value of $<0.001$. Comparison of the MCQ between the two groups shows that MCQ is higher online consultation based learning group with a $t$ value of 8.062 and is statistically significant with a $p$ value of $<0.001$. Comparison of the MCQ-After between the two groups shows that MCQ-After is higher in online consultation based learning group with a t value of -9.531 and is statistically significant with a $\mathrm{p}$ value of $<0.001$. Comparison of the MCQ Difference between the two groups shows that MCQ Difference is higher in Traditional group with a $t$ value of 0.804 and is statistically non-significant with a p value of 0.424 .

Online classroom, on comparison of the mean values of MCQ and MCQ-After the mean values of MCQ is higher with a difference of 2.08 is statistically significant with a $\mathrm{p}$ value of $<0.001$. Online clinical consultation, on comparison of the mean values of MCQ and MCQ-After the mean values of MCQ is higher with a difference of 1.72 is statistically significant with a $\mathrm{p}$ value of $<0.001$.

This lock-down when announced last month halted all forms of academics that were happening in the nation. This condition was never expected and perhaps the teaching fraternity was never exposed to such conditions. But since everything happened in a flash there was no scope for planning. Everyone in academics was involved to come up with ways to handle the situation. And the faculty with their thinking caps on, against all odds, was able to come up with the solution of online teaching through an interface called a ZOOM cloud meeting. Now since this mode of teaching is taking place in the college, it is the time to understand the student's perceptions and the actual effectiveness of the programme.

\section{Conclusion}

The online consultation based teaching is far superior when compared to online classroom based teaching. This study is intended to be very useful to academicians who teach Dermatology in Medical Schools.

\section{References}

1. Mukhtar K, Javed K, Arooj M, Sethi A. Advantages, limitations and recommendations for online learning during COVID-19 pandemic era. Pak J Med Sci 2020;36(COVID19 S4):S27-S31.

2. Kaliyadan F, Manoj J, Dharmaratnam AD, Sreekanth G. Self-learning digital modules in dermatology: A pilot study. J Eur Acad Dermatol Venereol 2010;24:655-60.

3. Schneider SL, Council ML. Distance learning in the era of COVID-19. Arch Dermatol Res 2020, P1-2. doi: 10.1007/s00403-020-02088-9.

4. Singh DG, Boudville N, Corderoy R, Ralston S, Tait CP. Impact on the dermatology educational experience of medical students with the introduction of online teaching support modules to help address the reduction in clinical teaching. Australas J Dermatol 2011;52:2649.

5. Scaperotti M, Gil N, Downs I, Jeyakumar A, Liu A, Chan $\mathrm{J}$ et al. Development and evaluation of a webbased dermatology teaching tool for preclinical medical students. MedEdPORTAL 2017;13:10619.

6. Chou WY, Tien PT, Lin FY, Chiu PC. Application of visually based, computerised diagnostic decision support system in dermatological medical education: A pilot study. Postgrad Med J 2017;93:256-9.

7. Gewin V. Five tips for moving teaching online as COVID-19 takes hold. Nature 2020;580:295-6.

8. Abi-Rafeh J, Azzi AJ. Emerging role of online virtual teaching resources for medical student education in 
plastic surgery: COVID-19 pandemic and beyond. J Plast Reconstr Aesthet Surg 2020;73:1575-92.

9. Guzman AK, Wang RH, Nazarian RS, Barbieri JS. Evaluation of YouTube as an educational resource for treatment options of common dermatologic conditions. Int J Dermatol 2020;59:e65-7.

10. Giroux CM, Moreau KA. Leveraging social media for medical education: Learning from patients in online spaces. Med Teach 2020, P1-6. doi: 10.1080/0142159X.2020.1779920. 